\title{
Parametric Investigation of Plane Frame Structure Using Excel Vba And Sap2000 oapi Based Programming
}

\author{
${ }^{*}$ Anthony Quansah ${ }^{1}$,Zhirong Xiao ${ }^{2}$, TresorNtaryamira ${ }^{3}$ \\ ${ }^{1}$ MSc, School of Civil Engineering and Architecture, Zhejiang University of Science and Technology, Zhejiang \\ Province, China \\ ${ }^{2} P h D$, School of Civil Engineering and Architecture, Zhejiang University of Science and Technology, Zhejiang \\ Province, China \\ ${ }^{3} \mathrm{MSc}$, School of Civil Engineering and Architecture, Zhejiang University of Science and Technology, Zhejiang \\ Province, China
}

Corresponding author:Anthony Quansah

\begin{abstract}
In this paper, effects of a critical structural parameter, beam-to-column stiffness ratio $(\rho)$ on seismic lateral force distribution and its corresponding displacement (s) on frame members were observed. For this purpose, analysis of 12 samples of a 10-storey frame structure having varying beam/ column stiffness was carried out with the help of software facilities. To save time in the modelling and parameterization of the frame structure, a programming tool has been developed combining the functionality of VBA based excel software, Matlab and SAP2000 OAPI. With the help of this tool, parametric analysis of a significant number of frame models can automatically be generated and executed in SAP2000 in a lesser time of 139.0secs and at a less expense of user input. The core interest in performing the analysis is to estimate the responses of varieties of weakcolumn/strong-beam and strong-column/weak-beam multi-story frame subjected to seismic lateral forces by modelling the frame in its actual form[SAP2000] and idealized stick model [hand computation]. From the analysis of the various models, comparison of SAP2000 lateral force distribution and displacement of frame models is made with that of hand calculation.
\end{abstract}

Keywords:SAP2000 API, beam-to-column stiffness ratio $(\rho)$, equivalent static analysis, and frame

\section{INTRODUCTION}

Complex modelling and analysis of civil engineering structures have been made easier for the past decades of years due to the availability and continual emergence of high processor-based computers and software. Many software developers nowadays have made the usage of their software very flexible through the provision of Application Programming Interface(APIs). The time-consuming factor of parametric studies is always unbearable to civil engineers and in our case, it left us with no option than to develop an interactive front-end tool by making use of the new SAP2000 API that automatically performs this task in less time. This developed tool can automate monotonous tasks and hence increases user productivity, eliminates user errors and ultimately guarantees a level of accuracy of pre-processing and post-processing analysis by the fact that its algorithm is based on SAP2000 API cutting-edge numerical modules.

Lateral displacement or drift of a frame structure under earthquake loading and wind loading is a critical parameter for structural evaluation or design because its magnitude indicates the damage state and the vulnerability of buildings. The damage of a structure can be controlled through monitoring its displacement under static analysis and a complex dynamic analysis. This analyses is executed in various structural software through the intricate modal and direct-integration methods like time history analysis which requires high processor demanding software. Though modern computing equipment has made it possible to perform these complex analyses, yet, there remains a need for a simple mathematical model that can be used to approximate, with a reasonable degree of accuracy, the response of building frames to loadings[1] using hand calculation especially at the preliminary stage.

Li,Bing[2], Heidbrecht et al.[3], Rutenberg, A.[4], Paulay and Priestly[5], N.Caterino[6] proposed models for estimating story lateral stiffness and these models are more flexible and can be applied to shear and flexure type frames for calculating lateral displacement. Muto (1974)[7] addressed an issue of 
approximating lateral stiffness of columns in elastic stories through the application of slope-deflection equations to members of a regular frame. According to Arturo E. Schultz[8], Muto's intermediate-story expression estimates the story stiffness with a tolerable degree of accuracy of $7 \%$ error and hence Schutlz modified it to a closest approximation and this expression is further used in this paper for computation. Even though it can be a challenging and time-consuming effort to evaluate structural components by hand calculation, it provides a designer with an alternative approach to verify results of a more sophisticated computer analysis during preliminary design.The equivalent static lateral force(ESLF) method is hence a simplified technique to substitute complex time history and response spectrum analysis in terms of evaluating structural dynamic response at the expense of hand calculation.

Understanding the parameters that define a model's performance is very important because it helps a designer to predict the structural behaviour in the preliminary stage. Hence parametric study is therefore carried out in the present study to investigate and understand the change in beamcolumn stiffness ratio on the equivalent static lateral force distribution and lateral displacement behavior of a low rise story frame structure.

\section{EQUIVALENT STATIC LATERAL ANALYSIS}

Experience in past earthquakes has demonstrated that many common buildings and typical methods of construction lack basic resistance to earthquake forces[9]. Hence, these basic resistances can be attained by following a simple, inexpensive design principles of seismic lateral forces. Equivalent static force analysis is a commonly used simple procedure for specifying basic seismic design lateral forces.

ESLA substitutes the effect of dynamic loading by a laterally distributed static force to help find the maximum displacement for design purposes [10]. The modelling principles for this design procedure requires that floor diaphragms be modeled as a series of lumped masses and columns be modelled as sticks assigned with individual equivalent floor stiffness [Fig. 1], henceforth referred as stick model. The distribution of this equivalent lateral static forces at each lumped mass is based on the fundamental mode of vibration of the multidegree of freedom (MDOF) system cantilevered structure[11]. Chinese Code for Seismic Design of Buildings, GB 50011-2010 is used as the main reference guide in the entire studies for seismic lateral force design. The base shear method is adopted and hence only one degree of freedom is considered for each story. A step-by-step procedure is put in Fig.2.
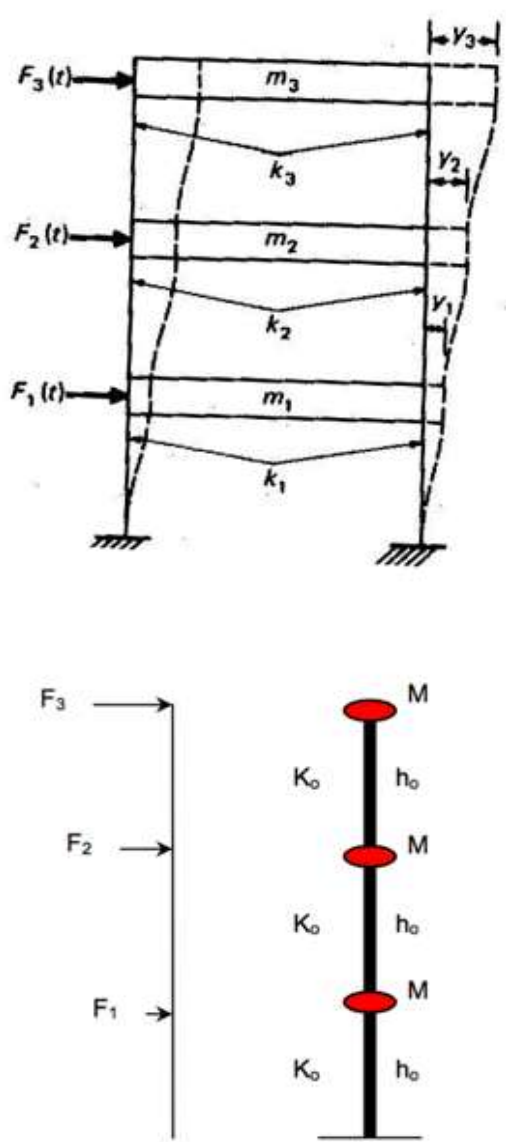
(a) Design
(b) Stick
forces
model

Fig -1: Two-bay model and stick model

\section{Single-Degree-Of-Freedom System}

A few techniques have been proposed or utilized as a part of previous research studies in which structures are modeled as single-degree-offreedom systems to assess their performance. The single-degree-of-freedom idealization emanate from linking the actual structure to an auxiliary rigid frame that makes the structure follow a specified deformation pattern[12]. Takizawa and Jennings [13]employed an equivalent single-degree-offreedom system to examine the ultimate capacity of ductile reinforced concrete frame structures under the combined action of strong ground shaking and gravity loads. In conjunction with derivation of statistical expressions, Bernal [14] reduced a multistory structure to an equivalent single-degreeof-freedom system to help correlate the minimum base shear coefficient needed to avert instability.

To implement single-degree-of-freedom in this study, floor diaphragm constraint will be set in the vertical[Z] direction and allow only displacement in $\mathrm{X}$-direction. 


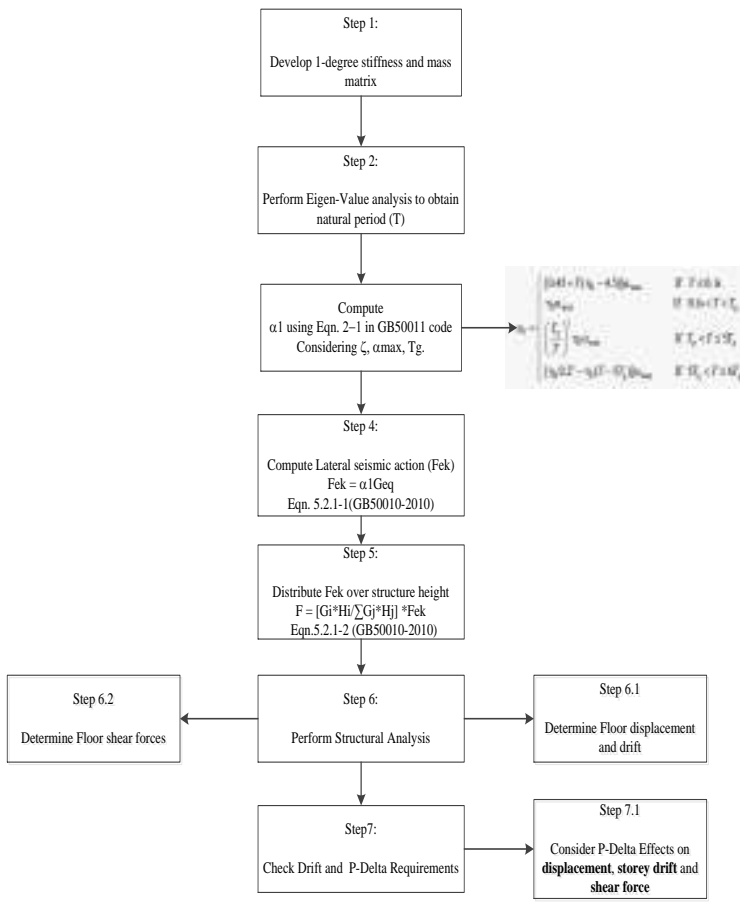

Fig -2. - Step by Step procedure for ESLA design per GB-50011-2010

\section{Structural Lateral Force Resisting System}

A lateral force resisting system(LFRS) is significantly accountable for earthquake effects like overturning, story drift and it rightfully defines a structure's lateral stiffness and strength properties.LFRS is tagged as either a moment resisting frame (MRF) or shear resisting frame (SRF) if it conceptually operates as strong-column/weakbeam with small beam/column stiffness ratio or operates as weak-column/strong-beam with high beam/column stiffness ratiorespectively[Fig.3]. Series of research works have investigated into the response of MRF under lateral force distribution but less research is done on SRF. Dynamic analyses conducted by Chao et al.[15], have shown that, as the beam-to-column stiffness $(\rho)$ decreases, the higher mode response becomes an increasing percentage of the total response, and Chao et al. [15] supported that, in the extreme case of beam stiffness approaching zero, the lateral forces at the upper levels of the frame become much larger. Nonlinear dynamic analyses carried out by Villaverde [16] has showed that, numerous upper story collapse due to these higher modes effects resulting from small beam-column stiffness ratio. LFRS behaves stiffer and vibrates with smaller period(T) at small beam-column stiffness ratio and itis found from Takizawa and Jennings [13] that, stiff structures have a much larger safety margin between damage and collapse than flexible structures.

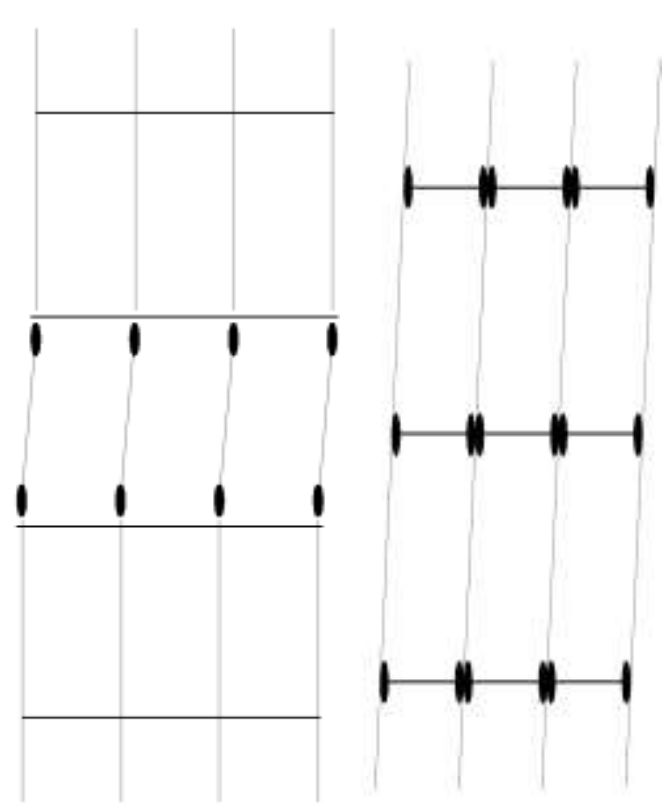

Fig -3: weak-column/strong-beam[Left] and strongcolumn/weak-beam[Right]

\section{OVERVIEW-OF-THE-SAP2000 APPLICATION-PROGRAMMING INTERFACE}

Based on the researcher's core aim and direction of analysis, it is of great urgency to streamline SAP2000 application through the use of API to make efficient use of its cutting-edge procedures and computational methods which can immensely enhancethe productivity and quality of its day-day usage. Current investigations have shown that, quite a handful number of research works put into operation the usage of SAP2000 API and its parent-application into wider research fields like modal pushover analysis of bridges etc.

\subsection{Description of the SAP2000 API}

The CSI Application Programming Interface is a powerful tool that allows users to automate many of the processes required to build, analyze and design models and to obtain customized analysis and design results. It also allows users to link SAP2000 with third-party software, providing a path for two-way exchange of model information with other programs through an established direct bind during run-time [fig. 4]. This two-way exchange of model information is captured in the flow chart [Fig. 2]. In terms of computer programming, the API mainly provides access to a cluster of objects and functions capable of extraneously controlling the behaviour of SAP2000, thereby, overriding the standard point-andclick procedure.[17]. The API is friendly with most major programming languages, including Visual Basic for Applications(VBA), VB.NET, C\#, C++, Visual Fortran, Python, and Matlab. 


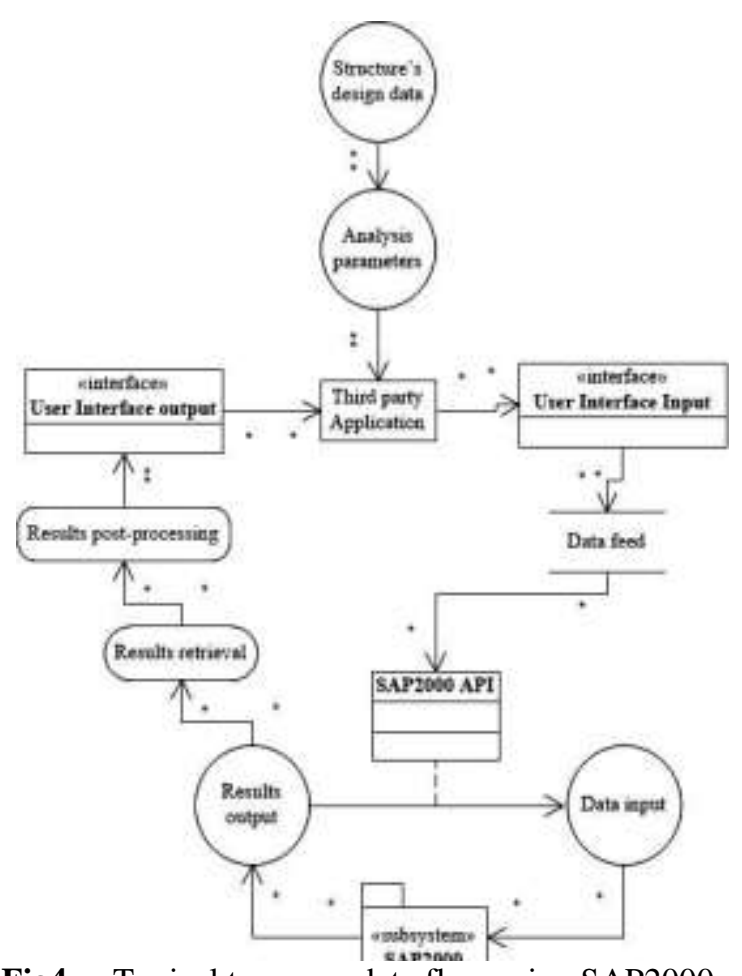

Fig4. - Typical two-way data flow using SAP2000 API

\subsection{Using the SAP2000 API}

The SAP2000 API requires an expertise level of programming background and skills during tool/plug-in development phase due to its robustness. Nonetheless, it can also be friendly to nonprogramming experts especially in the case of developing simple computing tools. Familiar users of Excel VBA and Matlab can easily establish two-way connection between these third party programs and SAP2000. A functional and complete SAP2000 installation is the first requirement in this API programming as it creates access to the API functions and class files.

Clinging to a more familiar third-party programming language is recommended, as the prospectivearrangement of the application to be developed as well as the language syntax differ in accordancewiththe languages standard. It should be bear in mind, however, that the programming style to which one is acclimatized to has to be suited to the way the API is integrated due to the fact that routines designed for a specific model might not be applicable to others.

\section{EQUIVALENT-STATIC-LATERAL ANALYSIS IMPLEMENTATION}

A profound planning and cognizant decisions concerning the usability, flexibility and front-end layout of the final tool is a very necessary requirement for the implementation of this analytical method. Developing a tool capable of applying the ESLA procedure to plane frame structures involves the consideration of a substantial amount of analysis parameters, i.e. elastic modulus(E), section inertia(I), floor mass(M), fundamental period (T), story height(h). Effective storage and management of a quite number of variables and provision of a granted ingress to important information at all the stages of the analysis is an improvise which introduces simplicity, integrity, optimization and supervision of the this applied procedure.

\subsection{Software architecture}

The software operates on a well-designed architecture which is accomplished through the use of SAP2000 API, Excel VBA and Matlab COM Server that aims to control the flow of data within the system [Fig. 5]. To ensure clarity, flexibility and easy debugging of the final product, excel VBA'scode block arranged in modules was established according to the tasks that are intended to perform. The user interaction is directed through three different functionalgraphical user interface (GUI), namely; "Welcome window", "Modelling window "and "Loading window" which contains all the components necessary to collect and transfer the required details to SAP2000 for frame modelling and property assignment. Underlying the GUI are series of excel sheets which serve as the database for storage and management of user input information. Linked to the loading window is the Matlab COM server which is used to perform the hand computation of Equivalent Static Lateral Force analysis during the pre-processing phase of analysis according to GB 50011-2010.

The output from Matlab hand computation is the seismic lateral force distribution to be applied to the SAP2000 modelled frame. SAP2000 is a dynamic software which has the capability to perform the ESLA according to GB 50011-2010 as well as other international standards. Per the final developed tool, the user has the options of designing the lateral force distribution by hand calculation approach[Matlab], SAP2000 approach or compare both. The final phase of the analysis is post-processing where the user has the ingress to view the final results which comprise of designed lateral force distribution performed by both Matlab and SAP2000 as well as the corresponding lateral displacements in excel worksheet format.

Parametric study can be performed through the interactive user interface as it provides input component to the user to enter the beam-to-column stiffness ratio at the initial run of the final product.

\subsection{Description of the implementation}

The technique that was selected in turn to implement the method of analysis absolves the restrictions of SAP2000's unilateral arrangement of analysis flow. This thereforeremarkablywidens the 
computational power that is available to the user. The concluding application provides the following features:

- Two-way collaboration between the application and the SAP2000 suite, by making use of the data exchange capabilities that the API offers.

- SAP2000 model loading of seismic lateral force designed by both hand calculation[Matlab] and SAP2000 auto seismic functionality, and allows for approach comparison.

- Visualization of the final frame deformed shape

- Easy post-processing operations as all necessary results after analysis are channeled to excel sheets.

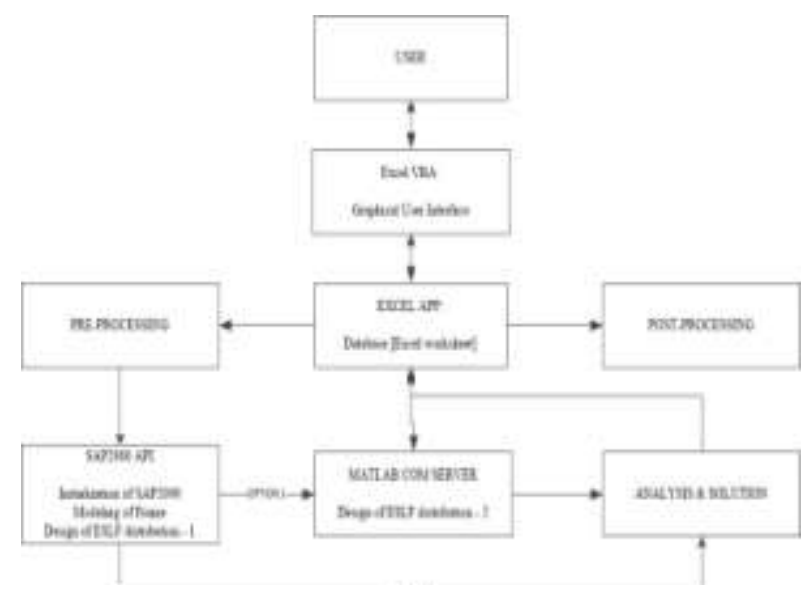

Fig5. - Equivalent Lateral Force Design \& Analysis software structure.

The implementation flow as described above is well structured in the flow chart shown below [Fig. 6]:

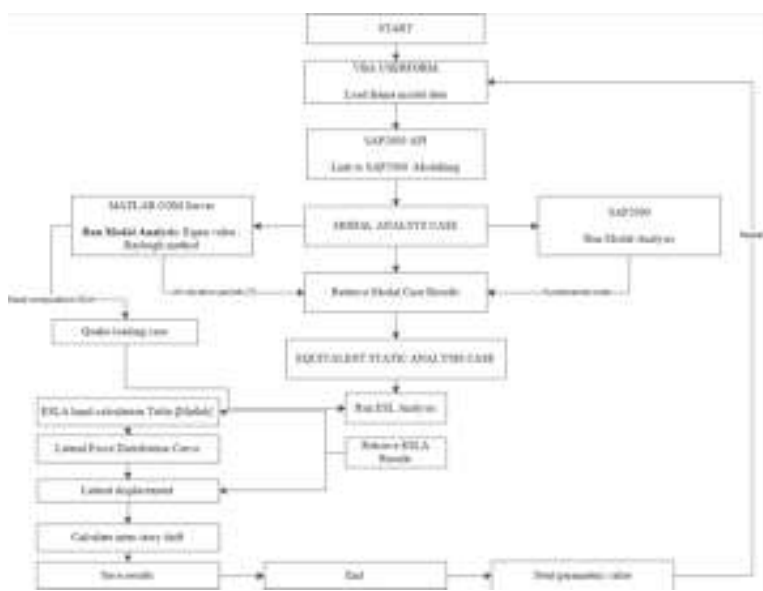

Fig6. - ESL Analysis software flowchart.

\section{APPLICATION FOR THE CASE OF SOME FRAME STRUCTURES STUDIED}

In order to present the capabilities of the developed software as well as investigate its accuracy and efficiency, it was deemed necessary to estimate the seismic assessment of a set of twelve samples of a ten-story plane frame structure, whose vertical configuration results to the GB-50011-2010 standard rule of vertical regularity. The next item in order is the description of the analysis procedure through the ESLA software.

\subsection{Description of studied frame models}

The frame selected for this task is a typical ten-story, five-span, regular frame [Fig.7], with a roof story modelled of a concrete material with elastic modulus (E); 28000e6 and rectangular cross-section assigned to all composing members. The total span length sums up to $24.00 \mathrm{~m}$ divided into spans of $4.80 \mathrm{~m}$, while the column members run $4.00 \mathrm{~m}$ long within the first story and $3.50 \mathrm{~m}$ within the remaining stories [Fig. 8]. The column end-joints in contact with the ground [at-grade level] are restrained in all degree of freedom [fixed restraint], while all other beam-column joints are restrained in all directions except the global X-direction.

\subsection{Preparation of the frame models}

It is a pre-requisite to have the structural model of the frame properly prepared, in accordance to certain standards that will enable achieve the goal of the research. This is summarized into the following steps:

- Definition of the geometrical characteristics of the structure, within the SAP2000 application, including member property assignment and joint restraint setting.

- Definition of gravity loads in the form a load pattern named "DEAD LOAD" referring to the self-weight of the members. Also, various story stiffness is hand computed and stored in ".xls" format.

- Generation of assembled joint masses via execution of modal analysis.

- Extraction of assembled joint masses for the various point elements across each floor level based on the "Dead Load" pattern and storing data in an ".xls" format.

- A new seismic load case "QUAKE" is requisite in order for the ESL force to be applied. This can be created either manually or automatically via the ESLA software's interface, at asubsequent stage of the procedure.

- Saving the model into a new file, or replacing the existing file with the extension ".sdb" and terminating the instance of SAP2000.

\subsection{Definition of analysis parameters}

Definition of the ESLA parameters is accomplished through the "Loading Window" [Fig.11, Fig.12] which emerges after the preparation and modelling of the frame structure is completed in the initial stage of the analysis. The parameters to be 
applied are declared to the user in an orderly arranged form of textbox inputs and combo-box selections in accordance to the GB-50011-2010 ESLA [Fig.10, Fig.11, Fig.12].

Fig8. - Dimension detail of frame structure.
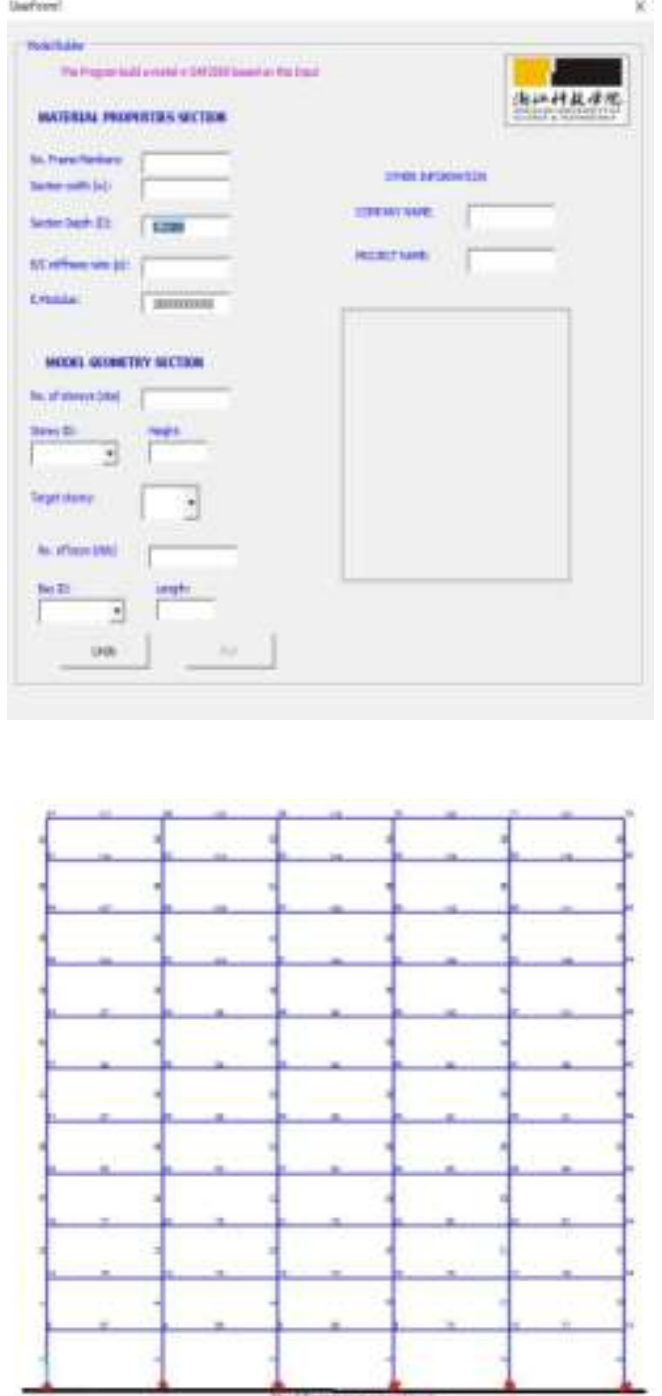

Fig7. - 10-storey + 1 roof level frame structure.

Much endeavor has been made, in order to keep the required analysis parameters to a minimum, self-interactive but adequate level. For the samples of frame models used for the case study, the ESLA parameters like structural ductility factor(mu), Return period factor(R), damping $\operatorname{ratio}(\mathrm{C})$, intensity(I), characteristics period $(\mathrm{T})$ were kept constant at a varied beam-to-column stiffness ratio. The user has the option to input a hand computed period into the ESLA software or maintain the SAP2000 computed fundamental period, however for this case study, program calculated period was maintained for consistency sake.

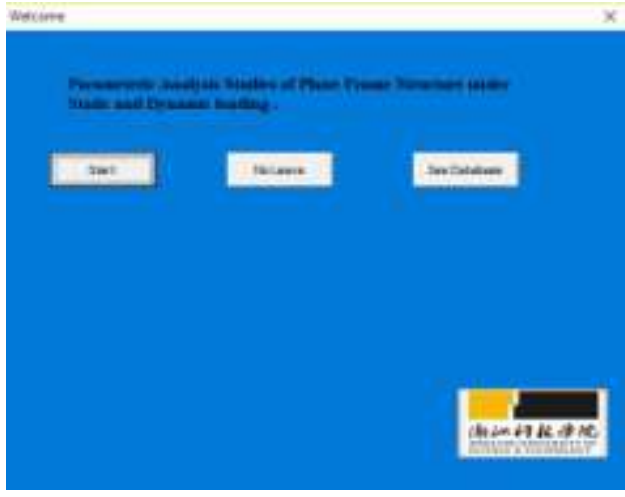

Fig9. - Welcome window at start-up.

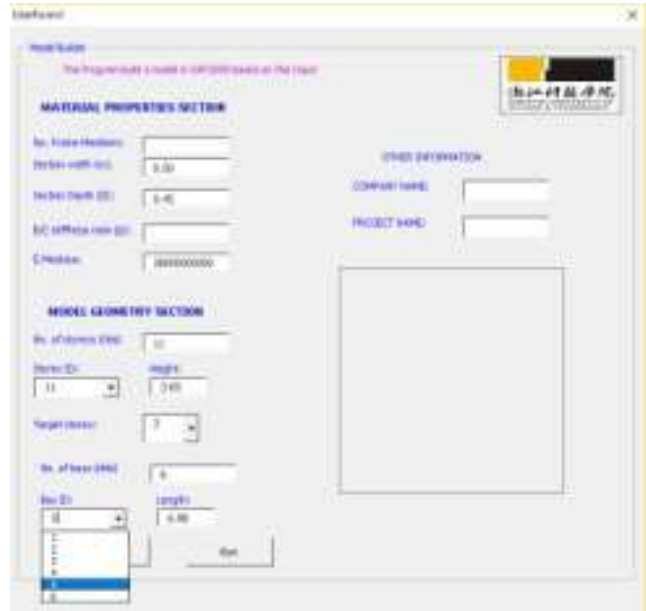

Fig10. - Model Builder window

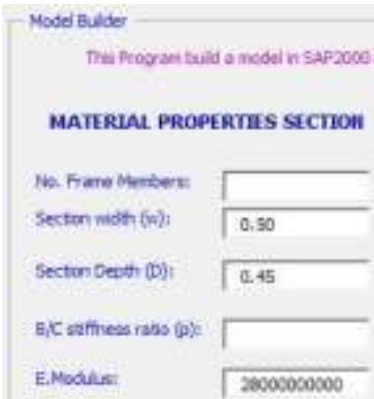

Fig11. - Material properties section.

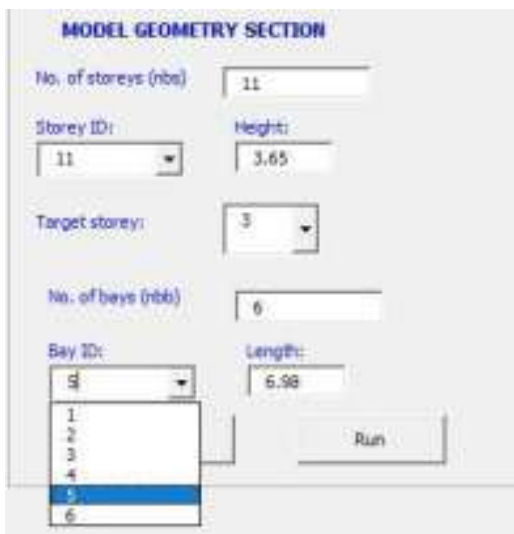

Fig12. - Model geometry section. 


\subsection{Analysis data for frame structure}

According to Chinese seismic codes GB 50011 from the following section;

Concrete grade $=\mathrm{C} 30[3.9 .2-$ The floor and roof shall be assumed as rigid, block rigid diaphragm]

Number of storeys in the structure $=10+1$ roof story Interstorey height $=3.5 \mathrm{~m}$

Ground story $=4.0 \mathrm{~m}$

Return Period factor, $\mathrm{Ru}=3.0$

Structural ductility factor, $\mu=1.3$

Site And Base $=$ Class III [3.3.3]

Seismic precautionary Intensity $=8$ [3.2.2]

PGA Zone $=0.20 \mathrm{~g}$ [Table 3.2.2]

$\alpha \max =0.16$

$\mathrm{Tg}=0.4$

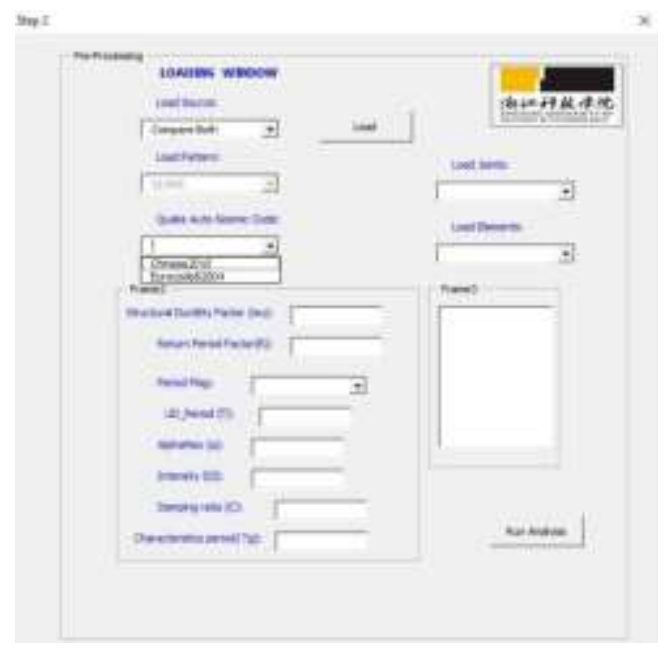

Fig11. - ESLA design window [Part I].

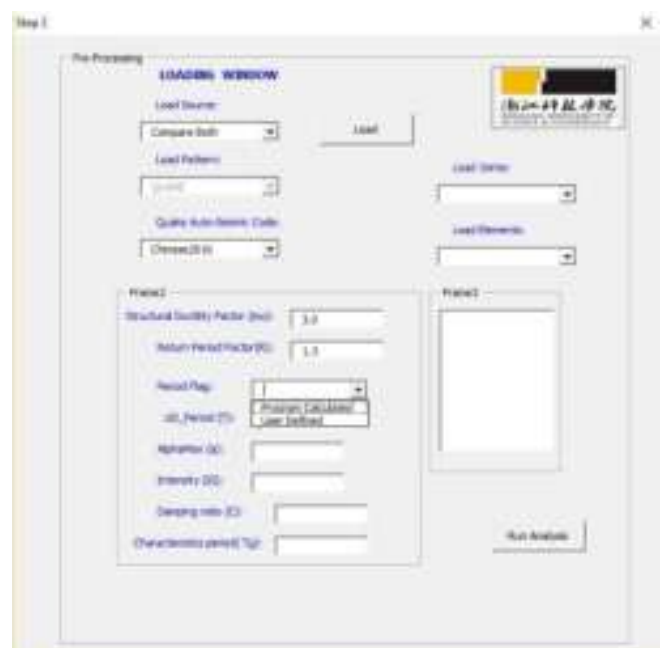

Fig12. - ESLA design window [Part II].

\subsection{Performing the analysis}

After analysis parameters are completely defined, ESLA procedure is automatically triggered to begin. Upon completion of the analysis, the ESLA table is retrieved and lateral force distribution designed by both SAP2000 and Matlab is made available.

Fig9. - Window showing the status and progress level during analysis.

\subsection{Results and Discussion}

The core interest in performing the analysis is to estimate the responses of varieties of weakcolumn/strong-beam and strong-column/weak-beam multi-story frame subjected to seismic lateral forces by modelling the frame in its actual form and idealized stick model. Range of beam/column stiffness ratio investigated are between 0.1 and 1.5. The general results as shown in Table 1 indicates that the stick model attracted higher base shear as compared to that of the actual frame.

Table -1: Design lateral forces and story shears for $10+1$ story-frame in X-Direction for $\square=0.2$

\begin{tabular}{|c|c|c|c|c|c|c|c|}
\hline Level & on & $\begin{array}{l}b_{1} \\
\text { (in) }\end{array}$ & $\alpha b^{\prime}$ & $\mathrm{C}_{a}$ & $\begin{array}{l}F_{1} \\
B_{1}\end{array}$ & $\begin{array}{l}y_{x} \\
D_{1}\end{array}$ & $\begin{array}{c}\text { Sipawo } \\
V_{X} \\
S_{1}\end{array}$ \\
\hline 11 & 1407753 & 25 & 54430 & 60489 & 1956 & 51864 & 3548 \\
\hline in & 50138 & 35 & (6963) & 6040 & 100364 & (9122) & 5441.7 \\
\hline 9 & 1901729 & 35 & $\sin 323$ & 10479 & 101474 & 8465? & 204 \\
\hline 8 & 190723 & is & 58130 & 6042 & ที1.7 & 32854 & 91803 \\
\hline 7 & porta & 15 & $4 x+30$ & 0.49 & 79276 & 2080 & $164+1.4$ \\
\hline 6 & 130023 & 35 & 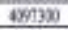 & 0048 & GISA & 54314 & 119237 \\
\hline 5 & 180629 & 35 & H.60 & 0040 & 92942 & 501515 & $12 m_{4}$ \\
\hline 4 & 1 wotr21 & 35 & $2 \times 130$ & 0.0427 & 49501 & 653212 & 11522 \\
\hline 3 & 1900729 & 5.5 & 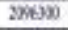 & 6648 & 3456.9 & SALES & 10518.3 \\
\hline 2 & 1812129 & 35 & 1695 & 8040 & $23 \times 8$ & 50334 & 145556 \\
\hline 1 & โ957ที & 49 & $\pi 1382$ & 0048 & $\lim 2$ & 710956 & 152107 \\
\hline $\bar{I}$ & xetwin & $y$ & & & 71645s & & \\
\hline
\end{tabular}

A visual presentation of this is shown in Fig.9. The fundamental period achieved with the stick model was smaller compared to that of the actual frame and this could be explained that the analytical stiffness model[Schutlz] used in the modelling of stick model's stiffness property renders it much stiffer and hence it will always attract higher seismic lateral forces especially at the upper story [Fig.14].

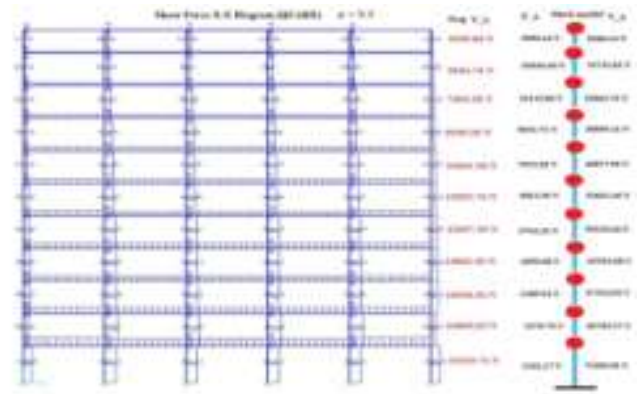

Fig9. - Visual presentation of shear force results for SAP2000 frame model and stick model.

According to Fig.10, which is a true representation of all twelve samples of parametric studies performed, the roof story deforms at a comparably higher displacement and maximum displacement is recorded for weak column/strong beam system with of 1.5 [Fig.11, Fig.12]. 


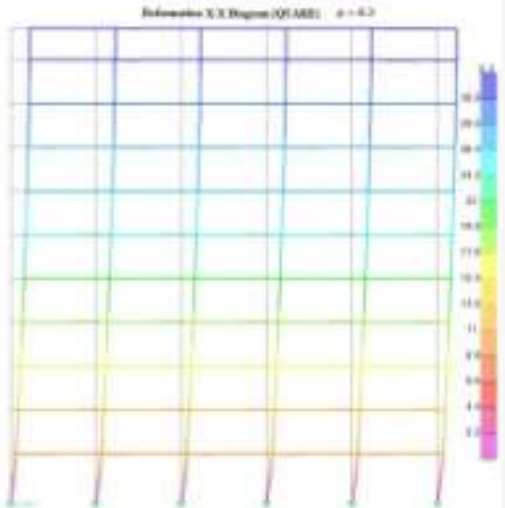

Fig10. - Visual presentation of shear force results for SAP2000 frame model and stick model.

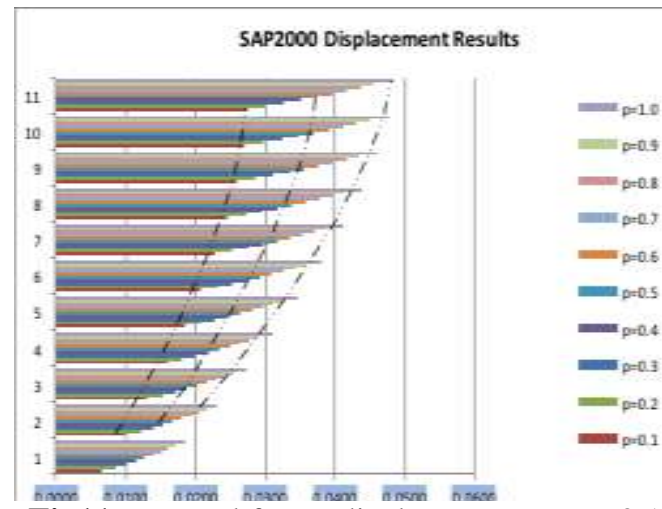

Fig11. - actual frame displacement at $\mathrm{p}=0.1$ 1.5

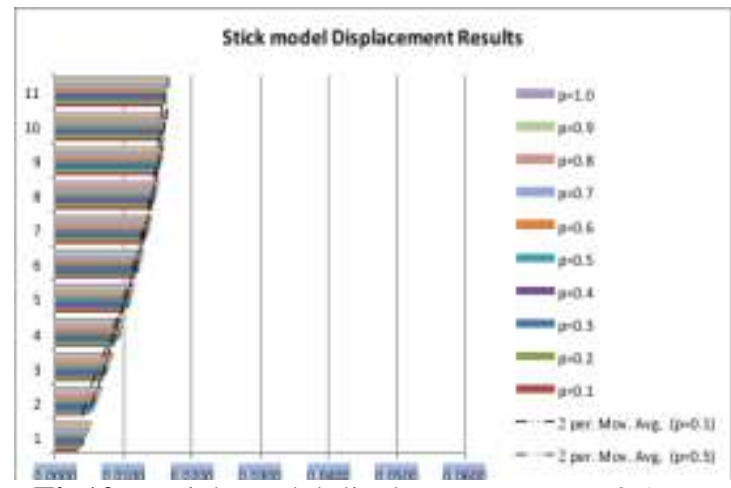

Fig12. - stick model displacement at $p=0.1-$ 1.5

The lateral force generated by the stick model is reduced at roof level for all the investigated scenarios of $\rho$ between 0.1 to 1.5 [fig.13]. Also the response of a system with $\rho$ equal to 1.0 is closer tothat of $\rho$ equal to 1.5 than to $\square \rho \square$ equal to 0.1 , which means a 50/50 SRF/MRF system behaves more like SRF than a MRF, meanwhile, a 35/75 $\mathrm{SRF} / \mathrm{MRF}$ system rather generates the average lateral force distribution [fig.13, fig.15].

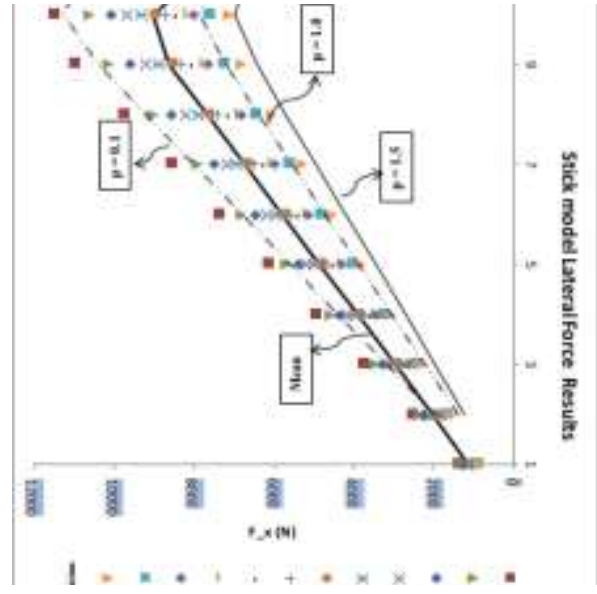

Fig13. - stick model designed lateral force at $p=0.1$ $-1.5$

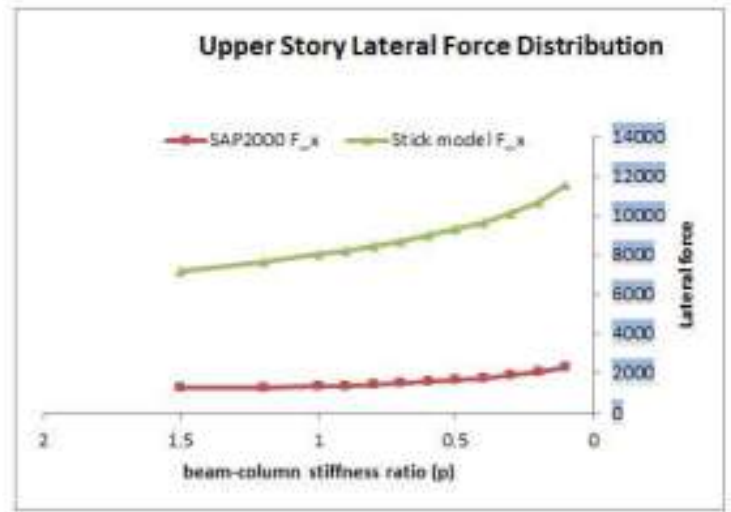

Fig14. - Upper story lateral force distribution at $\mathrm{p}=$ $0.1-1.5$

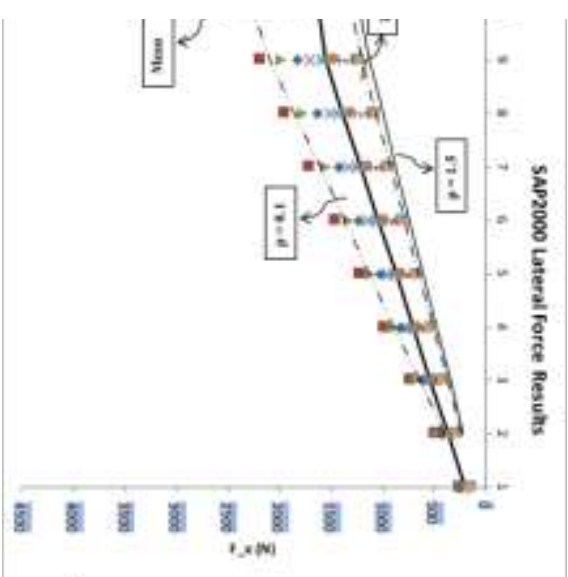

Fig15. - actual frame designed lateral force at $\mathrm{p}=$ $0.1-1.5$

The GB-50011 seismic code recommends that the seismic lateral force at roof story be modified by factor $\delta \mathrm{n}$ which choice of selection is based on the frame's characteristics period $\left(\mathrm{T}_{\mathrm{g}}\right)$ and fundamental period $(\mathrm{T})$. The stick model always bears smaller vibration period which hence accounts for a zero $\delta n$ and therefore reduces the upper story lateral 
force[fig.13]. From fig. 16, it is realized that much care needs to taken when a frame is operating between $\square \rho=0.1$ and 0.3 as any slight increase in properties sharply affects it vibration behaviour as compared to $\square \rho=0.4$ and 1.5 systems.

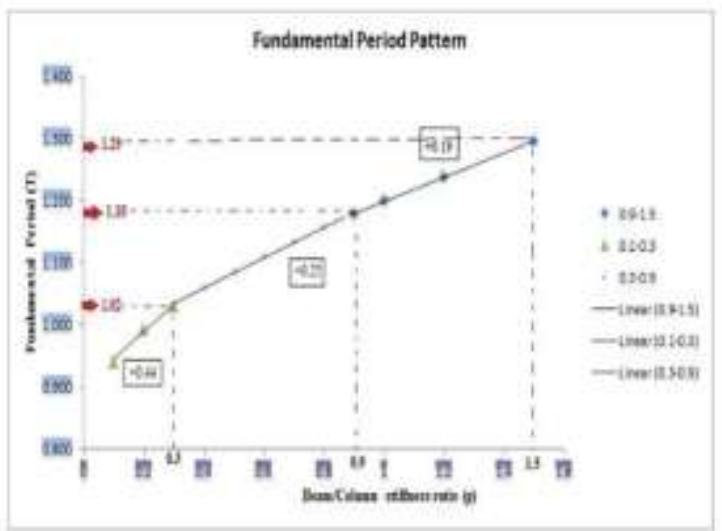

Fig16. - Fundamental period pattern between $\mathrm{p}=0.1$

$$
-1.5
$$

\section{CONCLUSIONS}

The problem of influence of beam-tocolumn stiffness ratio on frame's lateral force generation during seismic is not well understood. The obscurity of this problem is mainly related to the selection of well-suitable range of beam-column stiffness ratio fit for frame structures to suffer less lateral displacements during the incidents of seismic forces. From research findings it is concluded that MRF system with beam-column stiffness ratio $(\rho)$ between 0.1 and 0.3 is enough for less lateral displacement but attracts comparably higher seismic lateral force. In the case when SRF/MRF system is required, beam-column stiffness ratio $(\rho)$ around 0.52 or slightly higher is considerable. The developed tool saved a significant amount of time during the parametric studies but combining high-memoryusage software like Matlab, SAP2000 and excel VBA requires high-processor and RAM size for successful and faster operation.

\section{ACKNOWLEDGEMENT}

I wish to thank my supervisor for her support and my colleague, Ntaryamira for his assistance.

\section{REFERENCES}

[1]. Schultz A E 1992 Approximating Lateral Stiffness of Stories in Elastic Frames J. Struct. Eng.118 243-63

[2]. Li Bing 2012 Initial Stiffness of Reinforced Concrete Columns and Walls 15th World Conf. Earthq. Eng.
[3]. Heidebrecht A C and Smith B S 1972 Approximate Analysis of Tall Wall Frame Building Structures (Department of Civil Engineering and Engineering Mechanics, Mcmaster University)

[4]. Rutenberg A and Heidebrecht A C 1975 Approximate analysis of asymmetric wallframe structures Build. Sci.10 27-35

[5]. T. Paulay and Priestley M J N 2009 References Seismic Design of Reinforced Concrete and Masonry Buildings (Hoboken, NJ, USA: John Wiley \& Sons, Inc.) pp 719-33

[6]. Caterino N, Cosenza E and Azmoodeh B M 2013 Approximate methods to evaluate storey stiffness and interstory drift of RC buildings in seismic area Struct. Eng. Mech.46 245-67

[7]. Mutō K 1974 Aseismic Design Analysis of Buildings (Maruzen)

[8]. Schultz A 1992 Approximating lateral stiffness of stories in elastic frames 118 24363

[9]. Chitte C J 2016 Assessment of Seismic Forces by Equivalent Static Force Analysis as Per IS 1893 ( Part I ): vol 4

[10]. Bourahla N 2021 Equivalent Static Analysis of Structures Subjected to Seismic Actions Encyclopedia of Earthquake Engineering ed M Beer, I A Kougioumtzoglou, E Patelli and I S$\mathrm{K}$ Au (Berlin, Heidelberg: Springer Berlin Heidelberg) pp 1-13

[11]. Kharmale S B and Ghosh S 2012 FOR DUCTILITY-BASED DESIGN OF STEEL PLATE 6

[12]. Irvine U C 2007 Methods to Assess the Seismic Collapse Capacity of Building Structures : State of the Art

[13]. Takizawa H and Jennings P C 1980 Collapse of a model for ductile reinforced concrete frames under extreme earthquake motions Earthq. Eng. Struct. Dyn.8 117-44

[14]. Bernal D 1992 Instability of Buildings Subjected to Earthquakes J. Struct. Eng.118 2239-60

[15]. Chao S, Eeri M, Goel S C, Eeri M and Lee S 2007 Distribution Based on Inelastic State $\mathbf{2 3}$ 547-69

[16]. Verde R V 1991 Explanation for the numerous upper floor collapses during the 1985 Mexico city earthquake Earthq. Eng. Struct. Dyn.20 223-41

[17]. Sextos A G and Balafas G K 2011 Using the New Sap2000 Open Application Programming Interface To Develop an Interactive Front-End for the Modal Pushover Analysis of Bridges Compdyn $2011201125-8$ 


\section{BIOGRAPHIES}

\begin{tabular}{|c|c|}
\hline & 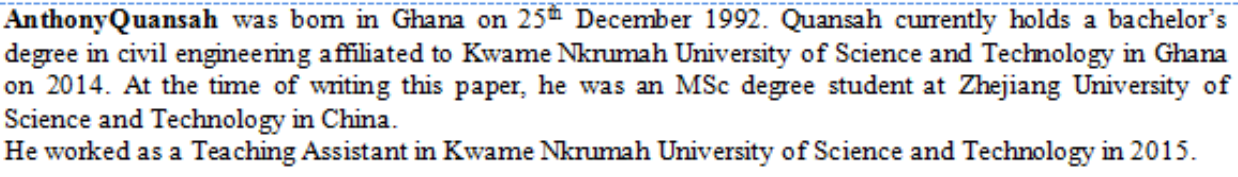 \\
\hline & $\begin{array}{l}\text { Zhirong Xiao was bom in China on } 1 \text { st March } 1974 \text {. } \\
\text { Xiao graduated from Zhejiang University in China with Ph. D. in Civil Engi } \\
\text { working in Zhejiang University of Science and Technology in China as an associ }\end{array}$ \\
\hline
\end{tabular}

Tresor Ntaryamira was born in Burundi on $28^{\text {th }}$ March 1990. Ntaryamira currently holds a bachelor's degree in civil engineering affiliated to Tongji University in China on 2014. At the time of writing this paper, he was an MSc degree student at Zhejiang University of Science and Technology in China.

Anthony Quansah. "Parametric Investigation of Plane Frame Structure Using Excel Vba And Sap2000 oapi Based Programming ." International Journal of Engineering Research and Applications (IJERA) 7.7 (2017): 14-23. 